\title{
Clusters of potential autonomous vehicles users according to propensity to use individual versus shared vehicles
}

Pettigrew, S. and Dana, L.M. and Norman, R.

\begin{abstract}
As the widespread use of autonomous vehicles (AVs) becomes increasingly likely, an important consideration is the extent to which individuals prefer either private ownership or shared use modes. Both modes are currently evolving, each with distinct but overlapping challenges. Understanding the preferences of different population segments can provide insights into where to focus initial efforts to attract individuals into the market, especially in terms of promoting the uptake of shared AVs to optimise the potential positive outcomes of AVs (e.g., crash reduction) while reducing possible negative outcomes (e.g., increased congestion). The results from a sample of 1,345 Australians aged 16+ years (97\% of whom were drivers) were analysed using latent profile analysis. Five discrete classes were identified on the basis of their (i) self-reported knowledge of AVs; (ii) perceptions of the positive and negative outcomes of AVs; and (iii) AV usage intentions. The classes were titled Nonadopters (29\% of the sample), Ride-sharing (20\%), AV ambivalent (19\%), Likely adopters (17\%), and First movers (14\%). The results indicate the types of individuals who may be most likely to be early adopters and the implications for public policies designed to encourage socially optimal forms of adoption.
\end{abstract}

Keywords: Autonomous vehicles, driverless cars, technology adoption, market segments. 


\section{Introduction}

The arrival of autonomous vehicles (AVs) will bring a variety of positive and negative outcomes. The potential benefits include crash prevention, enhanced mobility for those unable to drive, emissions reduction, and increased safety for pedestrians and cyclists (Bajpai 2016; Crayton and Meier 2017; Fagnant \& Kockelman 2015; Fleetwood 2017; Kelley 2017; KPMG 2015; Millard-Ball 2018). In Australia, the context of the present study, the cost savings related to crashes alone are estimated to exceed $\$ 16$ billion per annum for a national population of just 25 million (Pettigrew 2017). The main potential negative outcomes include increased overall road use and congestion (due to more people being able to use cars) and job losses and workplace changes among those in driving-related occupations (Hensher 2018; König and Neumayr 2017; Nielsen and Haustein 2018; Snyder 2016).

The extent to which these positive and negative outcomes eventuate will depend largely on (i) the speed and comprehensiveness of driver adoption of the new technology and (ii) the specific modes of vehicle autonomy that come to dominate (Bansal, Kockelman, and Singh 2016). In terms of adoption patterns, the largest benefits are forecast to accrue when most or all vehicles are automated and connected because this will permit maximum safety improvements and traffic efficiency (Duranton 2016). Public attitudes to AVs will determine how quickly they are adopted and hence the timeframe in which optimal benefits can be achieved (Hohenberger, Spörrle, and Welpe 2016; Menon et al. 2016; Pettigrew, Talati, and Norman 2018).

The main AV usage modes under discussion are individual ownership of AVs (e.g., Tesla cars) and ridesharing AVs (e.g., Uber and Waymo’s autonomous ridesharing services). 
However, hybrid scenarios are also likely in the longer term, such as 'first mile, last mile' systems in which shared AVs deliver travellers to and from public transport stations (Bösch et al. 2018). An extension of this is the 'Mobility as a Service' (MAAS) scenario that involves automated trip planning across multiple forms of transport such that the various transport legs are synchronised to achieve trip optimisation (Jittrapirom et al. 2017). The exact way in which AVs will be used will remain speculative until adequate penetration has occurred to allow observation of how transportation trends evolve over time (Nielsen and Haustein 2018).

As illustrated by the potential positive and negative outcomes listed above, there are important public policy implications of AV technologies (Clark, Parkhurst, and Ricci 2016). However, the financial imperatives of the major players are likely to result in the prioritisation of scenarios with the greatest profit potential rather than the scenarios with the greatest societal benefit (Hensher 2018). For example, conventional car manufacturers may work towards the dominance of private AV ownership because this most closely resembles their current business model. However, this may not result in optimal implementation due to the negative implications for traffic congestion (Lavieri et al. 2017; Ro and Ha 2017) and the lack of consideration of key groups that may have much to benefit from AVs but are unlikely to represent the most profitable target segments (e.g., the elderly and the disabled (Pettigrew, Cronin, and Norman 2018)). By comparison, shared AV modes have the potential to reduce the total number of vehicles in circulation (resulting in fewer physical and financial resources invested in vehicles that lie dormant most of the time), avoid the additional congestion that would result from empty vehicles traversing the roads, reduce the cost per mile to users, and decrease the amount of space that needs to be allocated to parking (Krueger, Rashidi, and Rose 2016, Lavieri et al. 2017). A further consideration is that these two usage scenarios 
(private ownership vs shared vehicles) are associated with different forms of infrastructure that will need to be accommodated by policy makers (Bansal et al. 2016). For example, continuing dominance of a private car model would result in the need for housing developments to be designed with substantial parking allocations and for pricing mechanisms to be applied to manage the increased congestion that would be likely to eventuate. By comparison, the dominance of shared AVs could result in the need to design communities around communal pick up points. Given the differing likely social outcomes and infrastructure requirements, it has been suggested that it is in governments' interests to encourage and facilitate a swift migration to a shared autonomous fleet and reduce the likelihood of widespread private ownership (Krueger et al. 2016; Haboucha, Ishaq, and Shiftan 2017).

An important element of the policy development and implementation process is to estimate likely levels of acceptance and resistance among the general public (Diepeveen et al. 2013). This information can inform planning processes, including the development of education programs to advise the general public of the nature of AVs and the advantages and disadvantages of different AV modes (Haboucha et al. 2017). Providing information about the potential benefits of AVs has been found to increase willingness to use these vehicles (Anania et al. 2018; Pettigrew et al. 2018), indicating the importance of ensuring that evidence provided to the public is accurate and balanced rather than dominated by sensationalised coverage of AV-related accidents.

\section{Literature review}

Research to date indicates that reasonable levels of support exist for AVs. Positive reactions have been found among substantial proportions of study participants, but with considerable 
variation depending on how the scenario was described. For example, Bansal et al. (2016) found that $80 \%$ of respondents in the US were at least slightly interested in owning an AV, while Pettigrew, Talati, and Norman's (2018) Australian study found that 37\% felt positively about the prospect of AVs being in widespread use and a further $40 \%$ reported being neutral on the topic. Similarly, Nielsen and Haustein's (2018) Danish study identified a segment they classified as AV enthusiasts (25\% of respondents) and another as AV indifferent (37\%).

A small but rapidly growing body of research has identified the consumer characteristics associated with positive and negative attitudes to AVs. Across studies conducted in various countries there are consistent trends, with males, younger people, and those living in urban areas tending to be more positively oriented to AVs (Bansal et al. 2016; Dong, DiScenna, and Guerra 2017; Hohenberger et al. 2016; König and Neumayr 2017; Krueger et al. 2016; Lavieri et al. 2017; Menon et al. 2018; Nielsen and Haustein 2018; Payre, Cestac, and Delhomme 2014; Pettigrew et al. 2018; Schoettle and Sivak 2014). Less work has assessed other characteristics, but there are indications that favourable attitudes are also positively associated with income (Bansal et al. 2016), education (Lavieri et al. 2017), being involved in more crashes in the past (Bansal et al. 2016), and having greater knowledge about AVs (Sanbonmatsu et al. 2018). The results relating to current patterns of car use appear to be mixed, although this may be at least partially the result of the differing ways in which this variable has been measured. Haboucha et al. (2017) found more favourable attitudes among those who spend more time driving, while König and Neumayr (2016) found attitudes to be more negative among those who use a car more often.

Compared to AVs in general, little is known about attitudes and intentions specifically relating to shared AVs. This is an important area of research given the relative benefits of 
shared AVs and therefore the need to understand overall acceptability and which population segments may be most amenable to this usage mode (Krueger et al. 2016). Achieving high levels of penetration within these segments as early as possible may produce favourable word-of-mouth communications and enhance visibility and awareness of shared AVs among other population sub-groups, thereby potentially increasing familiarity and ultimately the speed with which the benefits of this form of transport can be realised across society (Bansal et al. 2016; Dong et al. 2017; Menon et al. 2016).

The limited available work on shared AVs to date suggests that they tend to be considered less positively than privately owned AVs (Haboucha et al. 2017; Nielsen and Haustein 2018), and as is the case for AVs in general, males and younger people are likely to be more interested than their female and older counterparts (Bansal et al. 2016; Krueger et al. 2016; Lavieri et al. 2017; Menon et al. 2018). In addition, those already adopting multi-modal travel patterns appear more amenable to shared AVs (Krueger et al. 2016; Sanbonmatsu et al. 2018). Pricing will be important to signal to consumers the relative benefits of shared versus private AVs and encourage socially optimal usage patterns (Hensher 2018). Haboucha et al. (2017) found that $75 \%$ of their study participants would be willing to use free shared AVs, highlighting the important role of well-placed taxes and subsidies in influencing travel behaviour.

The present study contributes to the limited evidence on travellers' attitudes to different forms of AVs by identifying latent clusters based on AV-related attitudes and intentions. A broad range of indicator and predictor variables was used to generate class profiles that structure the Australian AV market. The results can inform the development of strategies designed to identify and target early adopters and promote uptake across the broader 
population. Relevant behavioural theories (e.g., the Technology Acceptance Model (Venkatesh, Morris and Ackerman 2000) and innovation diffusion theory (Rogers 2002)) emphasise the importance of numerous factors in determining adoption rates and patterns. These factors include the relative advantage of the innovation compared to existing alternatives, ease of trial, attitudes to using the innovation, and the extent to which use of the innovation is observable and therefore motivating to others. Identifying early adopters and facilitating their uptake of the technology can thus assist in promoting AV use at the population level by demonstrating ease and efficacy of use.

\section{Methodology}

\section{Sample}

As part of a larger research project investigating various aspects of AV adoption (Authors 2018), 1,624 Australians aged 16+ years completed an online survey administered by an accredited web panel provider (PureProfile). The minimum age threshold was determined according to the youngest age at which Australians can commence driving on public roads. Quotas were used to achieve a uniformly distributed sample across gender (male, female) and age categories (16-30 years, $31-50$ years, $50+$ years).

\section{Survey instrument}

The online survey instrument contained 44 items, including those relating to respondents' sociodemographic characteristics, preferred forms of transport, attitudes to AVs, and intentions to purchase and use AVs as outlined below (measures shown in Table 1). Ethics approval for the study was obtained from a University Human Research Ethics Committee. 
Sociodemographics: Respondents were asked to report their gender, age, level of education, and annual gross household income. They also reported whether they had dependent children or responsibility for transporting anyone with special care needs (e.g., the elderly or the disabled).

Driving history: Collected information related to number of years driving, number of crashes/accidents as a driver over the past 10 years, number of crashes/accidents as a passenger over the past 10 years, and whether they had ever lost their licence. Respondents with a driver's licence also rated the frequency with which they enjoy driving $(1=$ Never to 5 $=$ Always $)$.

AV knowledge: Respondents were asked "How much do you know about fully autonomous vehicles?", with response options ranging from 1 (Nothing at all) to 4 (A large amount).

Purchase/use intentions: The likelihood of (1) being one of the first to purchase an AV, (2) ever purchasing an $\mathrm{AV}$, and (3) using an autonomous vehicle ride sharing service was rated on 5-point scales ranging from 1 ('Very unlikely') to 5 ('Very likely').

Perceived benefits of AVs: Respondents rated the perceived likelihood of four positive outcomes predicted to result from the introduction of AVs: fewer traffic accidents, greater mobility for those who can't drive, more enjoyable travel time due to the ability to engage in leisure activities, and more productive travel time due to the ability to work in transit (Bansal et al. 2016; Fagnant \& Kockelman 2015; Schoettle \& Sivak 2015). Responses were measured on 5-point scales ranging from 1 (Very unlikely) to 5 (Very likely) and summed to generate a composite score. 
Concerns about AVs: Respondents rated their level of concern about two potential concerns relating to the introduction of AVs: safety and job losses (e.g., truck and taxi drivers) (Ro and Ha 2017; Snyder 2016). Response options ranged from 1 (Extremely concerned) to 5 (Not at all concerned). For analysis purposes, the responses were reverse coded and summed to produce a composite score.

Alcohol intake: As per national drug use surveys (Australian Institute of Health and Welfare 2017), respondents reported the frequency with which they consume alcohol ( $0=\mathrm{I}$ don't drink to $7=$ Drink every day) and the number of standard drinks usually consumed on a drinking day (response options ranged from 1 (Half a drink) to 11 (20 or more drinks)). Responses to these items were used to compute average daily intake. Those drinking an average of more than two standard drinks per day were classified as drinking at levels associated with long-term harm from alcohol (as per NHMRC 2009).

\section{Insert Table 1 about here}

\section{Data analysis}

Latent profile analysis (LPA: Hagenaars \& McCutcheon, 2009) was employed to categorise participants into classes reflecting their receptiveness to autonomous vehicles. The indicator variables used to constitute the models were perceived knowledge of AVs, likelihood of being one of the first to purchase a personal AV, likelihood over ever purchasing a personal $\mathrm{AV}$, likelihood of using an autonomous vehicle ride sharing service, perceived benefits of AVs, and concerns about the introduction of AVs. Respondents reporting "I don't know" for any of the perceived benefits or concerns indicator variables were excluded from the 
analyses, resulting in a final sample size of 1,345. One- through seven-class solutions were assessed using the maximum likelihood estimator in STATA version 15.

The fit statistics indices Akaike's Information Criterion (AIC), the Bayesian Information Criterion (BIC), and entropy were examined to identify the best fitting model. Lower AIC and BIC values combined with a relatively high entropy are indicative of an optimal class solution (Akaike, 1974; Nylund, Asparouhov, \& Muthén, 2007). Depending on the nature of the variables, one-way ANOVAs or chi-square tests were then conducted to explain the characteristics of those allocated to each profile class.

\section{Results}

\section{Total sample outcomes}

Table 2 shows the composition of the sample used for analyses $(n=1,345)$. Consistent with the stipulated quotas, the sample comprised almost equal splits for gender (51\% males) and the three age groups of $16-30,31-50$, and $51+$ years $(34 \%, 34 \%$, and $32 \%$ respectively). In addition, the proportion of drivers in the sample $(97 \%)$ reflects national prevalence (Charting Transport, 2015). Respondents' self-reported knowledge of AVs was low ( $M=2.10$ on a 4point scale, $\mathrm{SD}=.67$ ). Of the three usage modes presented (each assessed on a 5-point scale), respondents were more interested in using ride-share AVs $(M=2.95, \mathrm{SD}=1.33)$ than ever purchasing $(M=2.80, \mathrm{SD}=1.31)$ or being one of the first to purchase a personal AV $(M=$ $2.00, \mathrm{SD}=1.19)$. Across the sample, the mean composite scores relating to anticipated positive and negative outcomes were 15.03 (out of a possible 20, SD =3.74) and 6.16 (out of a possible $10, \mathrm{SD}=2.14)$, respectively. 


\section{Latent profile analysis outcomes}

The models with one through seven latent classes were compared based on the criteria listed above (results shown in Table 3). The five profile class model resulted in the lowest values for AIC and BIC and also exhibited the highest entropy of .89 , indicating that approximately nine-tenths of respondents were correctly classified into the appropriate profile class $(\geq .80$ indicates high classification quality: Clark \& Muthen 2009). The results of the fit statistics thus best supported the five class model.

\section{Insert Table 3 about here}

The means of each class compared to the entire sample were used to interpret the profile solution presented in Table 4 and depicted in Figure 1. Participants in Class 1 constituted $29 \%$ of the total sample and scored lowest for all but one of the indicator variables. The exception was the composite variable relating to concerns about AVs, for which respondents allocated to Class 1 demonstrated the highest scores. This class was thus interpreted as being strongly disinterested in adopting AVs and correspondingly titled "Non-adopters". In terms of other characteristics, members of this group were more likely to be older, be on lower incomes, have longer driving histories, and be less likely to have been involved in crashes than members of most other classes.

Insert Table 4 about here

Insert Figure 1 about here 
Class 2 (20\% of the sample) was differentiated from the other classes by very low reported intentions to be early adopters of AVs while demonstrating among the highest intentions to use shared AVs. They had relatively high expectations of positive outcomes from AVs and relatively low levels of concern. This class was titled "Ride-sharing preference". There were no predictor variables for which members of this group were significantly different to those in most other classes.

Class 3 (19\% of the sample) appeared to have no defining characteristics other than scoring mid-range on all indicator variables relative to the other classes. Reflecting these results, this group was titled "AV ambivalent". As was the case for Class 2, there were no significant differences in predictor variables that differentiated members of this group from those in most other classes.

Class 4 contained $17 \%$ of the sample and was characterised by relatively high scores for being an early adopter or an ever buyer and having the lowest reported levels of concern. This group was given the title "Likely adopters". As was the case for Classes 2 and 3, this group did not score significantly differently on the predictor variables relative to most other classes.

Class 5 was the smallest class, accounting for $14 \%$ of the total sample. Individuals in this group reported the highest scores on all indicator variables except concerns, for which they were the lowest (albeit the difference from the total sample mean for concerns was nonsignificant). The highly favourable attitudes towards both personal and shared AVs resulted in this group being classified as "First movers". Relative to those allocated to most other 
classes, members of this group tended to be more educated, have shorter driving histories, enjoy driving, and report regularly transporting the elderly/disabled.

\section{Discussion}

Governments have a key role to play in influencing the AV implementation process to ensure the potential benefits for society are achieved (House of Lords 2017). This role is likely to include developing and administering strategies designed to encourage the availability and take-up of more socially and environmentally favourable AV options (Haboucha et al. 2017; Krueger et al. 2016). The aim of the present study was to examine Australians' attitudes to the adoption of both personal and shared AVs to facilitate identification of population segments with varying levels of receptiveness to assist strategy development. In accordance

with innovation diffusion (Rogers 2002) and technology acceptance theories (Venkatesh et al. 2000), specific population segments can be expected to adopt AV technologies earlier than others, and these segments play an important role in influencing broader social uptake by making usage visible, providing opportunities for trial, and generating positive word-ofmouth communications about the benefits of the new technology (König and Neumayr 2016). It is thus especially important for policy makers and manufacturers to understand how best to develop specific strategies to facilitate uptake among those who are amenable to early adoption, as well as encourage AV use among the general population via broader approaches.

In this Australian sample, knowledge of AVs was low, interest in using AVs was moderate, and the ridesharing usage mode was found to be more popular than owning a personal AV. These results indicate that there is great potential to provide the general public with the additional information they need to make more informed assessments of the relative 
advantages and disadvantages of this emerging form of transport. The preference for shared $\mathrm{AVs}$ is a positive outcome given the greater potential for this usage mode to ameliorate the potential negative outcomes associated with widespread ownership of personal AVs (e.g., increased congestion and the environmental implications of the production and use of a larger number of vehicles once more people can own and use them: Fagnant and Kockelman 2015; Lavieri et al. 2017; Thomopoulos and Givoni 2015).

Using a latent profiling approach, five distinct market segments were identified on the basis of respondents' AV-related knowledge, attitudes, and behavioural intentions across both personal and shared usage modes. There are several noteworthy points about the nature of the identified segments. First, only the two extreme classes (Class 1: Non-adopters and Class 5: First movers) exhibited clear distinguishing characteristics relative to the sample as a whole. Second, the distinguishing characteristics of members of these two classes generally related to different predictor variables. Age (higher), income (lower), attitude to driving (greater enjoyment), driving history (longer), and number of crashes (lower) were significant predictors of whether individuals were categorised as Non-adopters. Of these variables, none differentially predicted membership of the First movers class except driving history, which was in the opposite direction to the Non-adopters (i.e., those categorised as First movers typically had shorter driving histories). Other variables that were especially relevant to First movers were (higher) education, driving enjoyment, and (greater) likelihood of transporting the elderly or disabled. It thus appears that the segments are substantively different than being polar opposites. The tendency for respondents allocated to this segment to report higher levels of driving enjoyment relative to other respondents is counter-intuitive and could benefit from further investigation. It could be that many of these individuals do not have much opportunity to drive anyway because of their reliance on public transport. 
Third, the remaining three segments (Ride-sharing, AV ambivalent, and Likely adopters) lacked defining characteristics relative to most of the other classes. This may reflect the overall low levels of AV knowledge that are preventing people from understanding the nature of these vehicles and their relative advantages and disadvantages (Pettigrew, Talati, and Norman 2018). It is also possible that other unassessed variables influence membership of these classes (e.g., risk-taking and sensation seeking: Kyriakidis et al. 2015; Payre et al. 2014).

Finally, overall there were very few age and gender differences between the segments, despite these variables being found to be important in numerous previous studies (Bansal et al. 2016; Dong, DiScenna, and Guerra 2017; Hohenberger et al. 2016; König and Neumayr 2017; Krueger et al. 2016; Lavieri et al. 2017; Menon et al. 2018; Nielsen and Haustein 2018; Payre, Cestac, and Delhomme 2014; Pettigrew et al. 2018; Schoettle and Sivak 2014). This outcome is likely due to the methodological approach adopted in the present study that involved the generation of latent classes that are based on variables associated with AVrelated knowledge, attitudes, and behavioural intentions. The interplay of these factors appears to have resulted in the weakening of demographic effects, which may make targeting more difficult because of the inability to use traditional consumer characteristics. Instead, the results suggest that it may be advantageous to focus on alternative factors that are directly related to the benefits of AVs (e.g., whether individuals have transportation responsibilities for dependents).

\section{Limitations and future research directions}


There were three primary limitations of the present study. First, the use of an online panel means that although quotas were used to ensure a sample with good population coverage, the resulting sample cannot be assumed to be representative of the Australian population. As such, future studies may use alternative data collection methods to provide a comparison point. Similarly, the respondents were from only one country and there is a need to determine whether similar class profiles exist elsewhere. Given the cultural similarities between Australia and most other industrialised nations, the results are likely to be informative for other contexts, but may not translate perfectly across countries. Finally, as noted above, although the present study included a wide and diverse range of variables, other factors that have been found to be associated with attitudes to AVs were not included (e.g., risk-taking and sensation seeking: Kyriakidis et al. 2015; Payre et al. 2014). Future research may include a broader range of potentially important factors to provide a more comprehensive analysis of the AV market segment structure.

A further important area for future research relates to the finding that one in four members of the 'First Mover' market segment reported responsibility for regularly transporting those who are unable to drive themselves (i.e., the elderly and the disabled). This presents an opportunity to develop service offerings and opportunities that are attractive to this group and those for whom they care to optimise the liberating potential of AVs. For example, many older people and those with disabilities rely on family, friends, and government-funded taxi voucher schemes to remain mobile, especially if they live in areas where public transport options are unavailable or unsuitable. The ability to summon door-to-door transport at any time at affordable cost could transform their lives, while also enabling those currently providing transport services to use their time in other ways (Pettigrew, Cronin, and Norman 2018). Research is needed to assess the extent to which these groups would be receptive to 
these services, the information they need to inform their transport choices, and their price sensitivity. An important component of such research would be exploration of the social issues associated with replacing human drivers with AVs. Increased mobility could result in greater overall human interaction due to the increased access to social events or activities such as grocery shopping and attending medical appointments. Alternatively, the removal of the driver from the transport process could result in a net loss in human contact for especially isolated individuals. Also of interest would be the time use changes for those who would otherwise provide transportation services for dependents. Measuring the nature and magnitude of these time trade-offs could provide insight into the complexity of social and economic outcomes that are likely to result from the widespread use of AVs.

Finally, attitudes and behavioural intentions relating to autonomous forms of public transport are an important area for future research. Acceptance of this form of shared AVs is critical for future transport planning because ultimately it is the most feasible approach to markedly reducing traffic congestion (Hensher 2018). Research is thus needed to canvass the public's attitudes to automated public transport to inform future strategies to promote acceptance, trial, and regular use of this form of AV technology once it is available.

\section{Conclusion}

The results of the present study indicate that Australians in general have low levels of knowledge about AVs, an outcome that reflects the early stage of the AV product life cycle (Rogers 2002). There is therefore substantial opportunity to provide the population with relevant and timely information about the nature of AVs and the relative merits of individual and shared AVs to promote socially beneficial patterns of AV adoption. Despite the recency of the advent of AVs, five market segments were identified with distinct profiles in terms of 
AV-related knowledge, attitudes, and intentions. These segments provide policy makers with some indication of the types of individuals who are likely to be key initial markets for both privately owned and shared AVs. In particular, those classified into the 'First Movers' group exhibited especially strong interest in both forms of AVs and are hence likely to be important influencers in terms of encouraging others to trial and adopt AVs. 


\section{References}

Akaike, H. (1974). A new look at the statistical model identification. Automatic Control, IEEE Transactions on, 19(6), 716-723.

Anania, E. C., S. Rice, N. W. Walters, M. Pierce, S. R. Winter and M. N. Milner (2018). "The effects of positive and negative information on consumers' willingness to ride in a driverless vehicle." Transport Policy. doi.org/10.1016/j.tranpol.2018.04.002

Australian Institute of Health and Walefare (2017). National Drug Strategy Household Survey (NDSHS) 2016: detailed findings. A. G. D. o. Health. Canberra, AIHW: 168. https://www.aihw.gov.au/getmedia/68bbff4e-f9c1-47c6-8682 9 dc90ab96d0c/ndshs2016-questionnaire.pdf.aspx.

Australian Bureau of Statistics (2013). 1270.0.55.005 - Australian Statistical Geography Standard (ASGS): volume 5 - remoteness structure, July 2011. http://www.abs.gov.au/ausstats/abs@.nsf/mf/1270.0.55.005?OpenDocument Authors (2018).

Bajpai, J. N. (2016). "Emerging vehicle technologies and the search for urban mobility solutions." Urban, Planning and Transport Research 4: 83-100.

Bansal, P., K. M. Kockelman and A. Singh (2016). "Assessing public opinions of and interest in new vehicle technologies: An Austin perspective." Transportation Research Part C: Emerging Technologies 67: 1-14.

Bösch, P. M., F. Becker, H. Becker and K. W. Axhausen (2018). "Cost-based analysis of autonomous mobility services." Transport Policy 64: 76-91.

Charting Transport. (2015). "Trends in driver's licence ownership in Australia" Charting Transport, March 9, 2015. 
Clark, B., G. Parkhurst and M. Ricci (2016). "Understanding the socioeconomic adoption scenarios for autonomous vehicles: A literature review." UK: University of West England. http://eprints.uwe.ac.uk/29134, accessed Jan 23, 2017.

Clark, S. L. and B. Muthen (2009). "Relating latent class analysis results to variables not included in the analysis." doi: http://www.statmodel.com/download/relatinglca.pdf.

Crayton, T. J. and B. M. Meier (2017). "Autonomous vehicles: Developing a public health research agenda to frame the future of transportation policy." Journal of Transport \& Health 6: 245-252.

Diepeveen, S., T. Ling, M. Suhrcke, M. Roland and T. M. Marteau (2013). "Public acceptability of government intervention to change health-related behaviours: a systematic review and narrative synthesis." BMC Public Health 13(1): 756. doi:10.1186/1471-2458-13-756.

Dong, X., M. DiScenna and E. Guerra (2017). "Transit user perceptions of driverless buses." Transportation: 1-16.

Duranton, G. (2016). "Transitioning to driverless cars." Cityscape 18(3): 193-196.

Fagnant, D. J. and K. Kockelman (2015). "Preparing a nation for autonomous vehicles: opportunities, barriers and policy recommendations." Transportation Research Part A: Policy and Practice 77: 167-181.

Fleetwood, J. (2017). "Public health, ethics, and autonomous vehicles." American Journal of Public Health 107(4): 532-537.

Haboucha, C. J., R. Ishaq and Y. Shiftan (2017). "User preferences regarding autonomous vehicles." Transportation Research Part C: Emerging Technologies 78: 37-49.

Hagenaars, J. A. P., \& McCutcheon, A. L. (2009). Applied Latent Class Analysis: Cambridge University Press. 
Hensher, D. A. (2018). "Tackling road congestion-What might it look like in the future under a collaborative and connected mobility model?" Transport Policy 66: A1-A8.

Hohenberger, C., M. Spörrle and I. M. Welpe (2016). "How and why do men and women differ in their willingness to use automated cars? The influence of emotions across different age groups." Transportation Research Part A: Policy and Practice 94: 374385.

House of Lords (2017). Connected and autonomous vehicles: The future?. UK: Science and Technology Select Committee. Available at https://publications.parliament.uk/pa/ld201617/ldselect/ldsctech/115/11502.htm

Jittrapirom, P., V. Caiati, A.-M. Feneri, S. Ebrahimigharehbaghi, M. J. Alonso González and J. Narayan (2017). "Mobility as a service: A critical review of definitions, assessments of schemes, and key challenges." Urban Planning 2(2): 13-25.

Kelley, B. (2017). "Public health, autonomous automobiles, and the rush to market." Journal of Public Health Policy 38(2): 167-184.

König, M. and L. Neumayr (2017). "Users' resistance towards radical innovations: The case of the self-driving car." Transportation Research Part F: Traffic Psychology and Behaviour 44: 42-52.

KPMG, C. (2015). "Autonomous vehicles - the UK economic opportunity." KPMG LLP, United Kingdom. https://www.smmt.co.uk/wp-content/uploads/sites/2/CRT036586FConnected-and-Autonomous-Vehicles-\%E2\%80\%93-The-UK-EconomicOpportu...1.pdf

Krueger, R., T. H. Rashidi and J. M. Rose (2016). "Preferences for shared autonomous vehicles." Transportation Research Part C: Emerging Technologies 69: 343-355. 
Kyriakidis, M., R. Happee and J. C. F. de Winter (2015). "Public opinion on automated driving: Results of an international questionnaire among 5000 respondents." Transportation Research Part F: Traffic Psychology and Behaviour 32: 127-140.

Lavieri, P. S., V. M. Garikapati, C. R. Bhat, R. M. Pendyala, S. Astroza and F. F. Dias (2017). "Modeling individual preferences for ownership and sharing of autonomous vehicle technologies." Transportation Research Record: Journal of the Transportation Research Board(2665): 1-10.

Menon, N., N. Barbour, Y. Zhang, A. R. Pinjari and F. Mannering (2018). "Shared autonomous vehicles and their potential impacts on household vehicle ownership: An exploratory empirical assessment." International Journal of Sustainable Transportation, DOI: 10.1080/15568318.2018.1443178.

Menon, N., Pinjari, A., Zhang, Y., \& Zou, L. (2016). Consumer perception and intended adoption of autonomous-vehicle technology: Findings from a university population survey. Paper presented at the Transportation Research Board 95th Annual Meeting, Washington, DC, January 10-14, 2016.

Millard-Ball, A. (2018). "Pedestrians, autonomous vehicles, and cities.” Journal of Planning Education and Research 38, 6-12.

National Health and Medical Research Council (2009). Australian Guidelines to Reduce Health Risks from Drinking Alcohol. Canberra: NHMRC.

Nielsen, T. A. S. and S. Haustein (2018). "On sceptics and enthusiasts: What are the expectations towards self-driving cars?" Transport Policy 66: 49-55.

Nylund, K. L., Asparouhov, T., \& Muthén, B. O. (2007). Deciding on the number of classes in latent class analysis and growth mixture modeling: A Monte Carlo Simulation study. Structural Equation Modeling: A Multidisciplinary Journal, 14(4), 535-569. 
Payre, W., J. Cestac and P. Delhomme (2014). "Intention to use a fully automated car: Attitudes and a priori acceptability." Transportation Research Part F: Traffic Psychology and Behaviour 27: 252-263.

Pettigrew, S. (2017). "Why public health should embrace the autonomous car." Australian and New Zealand Journal of Public Health 41(1): 5-7.

Pettigrew, S., Z. Talati and R. Norman (2018). "The health benefits of autonomous vehicles: public awareness and receptivity in Australia." Australian and New Zealand Journal of Public Health. doi.org/10.1111/1753-6405.12805.

Pettigrew, S., S.Cronin and R. Norman (2018). "The unrealized potential of autonomous vehicles for an aging population." Aging \& Social Policy. dio: $10.1080 / 08959420.2018 .1500860$

Ro, Y. and Y. Ha (2017). "A Factor Analysis of Consumer Expectations for Autonomous Cars." Journal of Computer Information Systems https://doi.org/10.1080/08874417.2017.1295791.

Rogers, E. M. (2002). “Diffusion of preventive innovations.” Addictive Behaviors 27(6); 989993.

Sanbonmatsu, D. M., D. L. Strayer, Z. Yu, F. Biondi and J. M. Cooper (2018). "Cognitive underpinnings of beliefs and confidence in beliefs about fully automated vehicles." Transportation Research Part F: Traffic Psychology and Behaviour 55: 114-122.

Schoettle, B. and M. Sivak (2015). "Motorists' preferences for different levels of vehicle automation." Transportation Research Institute, University of Michigan. https://deepblue.lib.umich.edu/bitstream/handle/2027.42/114386/103217.pdf.

Schoettle, B. and M. Sivak (2014). "A survey of public opinion about autonomous and selfdriving vehicles in the US, the UK, and Australia." Transportation Research Institute, 
University of Michigan. Available at

https://deepblue.lib.umich.edu/handle/2027.42/108384.

Snyder, R. (2016). "Implications of autonomous vehicles: a planner's perspective." Institute of Transportation Engineers. ITE Journal 86(12): 25.

Thomopoulos, N. and M. Givoni (2015). "The autonomous car-a blessing or a curse for the future of low carbon mobility? An exploration of likely vs. desirable outcomes." European Journal of Futures Research 3(1): 14.

Venkatesh, V.V., M.G. Morris and P.L. Ackerman (2000). “A longitudinal field investigation of gender differences in individual technology adoption decision-making processes.” Organizational Behavior and Human Decision Processes 83(1): 33-60. 
Table 1. Measures

\begin{tabular}{|c|c|}
\hline Variables & Measures \\
\hline \multicolumn{2}{|l|}{ Sociodemographic } \\
\hline Age & Open ended \\
\hline Gender & Males, Females \\
\hline Location & Metropolitan, Regional \\
\hline Highest educational qualification & $\begin{array}{l}\text { Five options: } 1=\text { No formal schooling/primary school to } 5= \\
\text { Postgraduate university degree }\end{array}$ \\
\hline Annual gross household income & $\begin{array}{l}\text { Seven options; } 1=\text { Less than } \$ 30,000 \text { to } 7=\$ 200,000 \text { or more } \\
\text { and } 8^{\text {th }}=\text { Prefer not to say }\end{array}$ \\
\hline Have a child(ren) & No, Yes \\
\hline $\begin{array}{r}\text { Responsible for transporting anyone with special care } \\
\text { needs (e.g. elderly or disabled) }\end{array}$ & No, Yes \\
\hline \multicolumn{2}{|l|}{ Driving history } \\
\hline Number of years driving & Less than one year, 1 to 3 years, 4 to 9 years, and $10+$ years \\
\hline No. of crashes in last 10 years as driver & None, $1,2,3-5$, and 6 or more \\
\hline No. of crashes in last 10 years as passenger & None, $1,2,3-5$, and 6 or more \\
\hline Ever lost driving licence & No, Yes \\
\hline Enjoyment from driving & On a five point scale $(1=$ Never to $5=$ Always $)$ \\
\hline \multicolumn{2}{|l|}{ Travelling time } \\
\hline Hrs per week on public transport for work commute & Open ended \\
\hline Hrs on public transport for other trips & Open ended \\
\hline Hrs driving per week for work commute & Open ended \\
\hline Hours driving per week for other trips & Open ended \\
\hline \multicolumn{2}{|l|}{ Alcohol intake } \\
\hline Frequency of alcohol consumption & On a 8-point scale: $0=\mathrm{I}$ don't drink to $7=$ Drink every day \\
\hline $\begin{array}{r}\text { the number of standard drinks usually consumed on a } \\
\text { drinking day }\end{array}$ & On a 11-point scale: $1=$ Half a drink to $11=20$ or more drinks \\
\hline Knowledge about AVs & On a 4-point scale ( $1=$ Nothing at all to $4=\mathrm{A}$ large amount $)$ \\
\hline \multicolumn{2}{|l|}{ Purchase/use intentions } \\
\hline First to buy AV & On a 5 -point scale: $1=$ Very unlikely to $5=$ Very likely) \\
\hline Ever buy AV & On a 5 -point scale: $1=$ Very unlikely to $5=$ Very likely) \\
\hline Share AVs & On a 5 -point scale: $1=$ Very unlikely to $5=$ Very likely) \\
\hline \multicolumn{2}{|l|}{ Perceived benefits of AVs } \\
\hline Fewer traffic accidents & On a 5-point scale: $1=$ Very unlikely to $5=$ Very likely) \\
\hline Greater mobility for those who can't drive & On a 5-point scale: $1=$ Very unlikely to $5=$ Very likely) \\
\hline $\begin{array}{r}\text { More enjoyable travel time due to the ability to engage } \\
\text { in leisure activities }\end{array}$ & On a 5 -point scale: $1=$ Very unlikely to $5=$ Very likely) \\
\hline $\begin{array}{r}\text { More productive travel time due to the ability to work } \\
\text { in transit }\end{array}$ & On a 5 -point scale: $1=$ Very unlikely to $5=$ Very likely) \\
\hline \multicolumn{2}{|l|}{ Concerns about AVs } \\
\hline Safety of the AV occupants and other road users & $\begin{array}{l}\text { On a 5-point scale: } 1=\text { Extremely concerned to } 5=\text { Not at all } \\
\text { concerned) }\end{array}$ \\
\hline Job losses (e.g., truck and taxi drivers) & $\begin{array}{l}\text { On a 5-point scale: } 1=\text { Extremely concerned to } 5=\text { Not at all } \\
\text { concerned) }\end{array}$ \\
\hline
\end{tabular}


Table 2. Sample table $(n=1,345)$

\begin{tabular}{|c|c|c|}
\hline Characteristic & $\mathbf{n}$ & $\%$ \\
\hline \multicolumn{3}{|l|}{ Age } \\
\hline 16-30 years & 455 & 34 \\
\hline $31-50$ years & 454 & 34 \\
\hline $51+$ years & 436 & 32 \\
\hline Mean age & 42 years $(S D=17.4)$ & \\
\hline \multicolumn{3}{|l|}{ Gender } \\
\hline Male & 689 & 51 \\
\hline Female & 656 & 49 \\
\hline \multicolumn{3}{|l|}{ Education } \\
\hline School & 435 & 32 \\
\hline Technical/trade certificate & 393 & 29 \\
\hline University degree & 517 & 39 \\
\hline \multicolumn{3}{|l|}{ Location } \\
\hline Metropolitan & 1,058 & 79 \\
\hline Regional & 287 & 21 \\
\hline \multicolumn{3}{|l|}{ Annual gross household income } \\
\hline Less than $\$ 30,000$ & 189 & 14 \\
\hline$\$ 30,000-\$ 74,999$ & 419 & 31 \\
\hline$\$ 75,000-\$ 149,999$ & 408 & 30 \\
\hline$\$ 150,000$ or more & 154 & 12 \\
\hline No response & 175 & 13 \\
\hline \multicolumn{3}{|l|}{ Driving status } \\
\hline Driver & 1301 & 97 \\
\hline Non-driver & 44 & 3 \\
\hline \multicolumn{3}{|l|}{ Vehicle ownership } \\
\hline Yes & 1,137 & 87 \\
\hline No & 164 & 13 \\
\hline \multicolumn{3}{|l|}{ Number of crashes in last 10 years as driver } \\
\hline None & 770 & 59 \\
\hline 1 & 304 & 23 \\
\hline 2 & 156 & 12 \\
\hline $3-5$ & 64 & 5 \\
\hline$\geq 6$ & 7 & 1 \\
\hline \multicolumn{3}{|l|}{ Number of crashes in last 10 years as passenger } \\
\hline None & 1,006 & 75 \\
\hline 1 & 214 & 16 \\
\hline 2 & 100 & 7 \\
\hline $3-5$ & 21 & 2 \\
\hline$\geq 6$ & 4 & $<1$ \\
\hline
\end{tabular}


Table 3. LPA fit indices for a one to seven-class solution

\begin{tabular}{lcccc}
\hline Model & Log-likelihood & AIC & BIC & Entropy \\
\hline 1 class & -14686 & 29397 & 29459 & - \\
2 class & -13775 & 27589 & 27688 & .84 \\
3 class & -13491 & 27033 & 27169 & .80 \\
4 class & -13408 & 26881 & 27053 & .75 \\
$\mathbf{5}$ class & $\mathbf{- 1 2 6 5 5}$ & $\mathbf{2 5 3 9 1}$ & $\mathbf{2 5 5 9 9}$ & $\mathbf{. 8 9}$ \\
6 class & -13127 & 26348 & 26592 & .85 \\
7 class & -13030 & 26169 & 26450 & .86 \\
\hline
\end{tabular}

Note: bold line indicates the best fitting model. 
Table 4. Results for indicator and predictor variables in the five-class model.

\begin{tabular}{|c|c|c|c|c|c|c|c|c|c|c|c|}
\hline \multirow[t]{2}{*}{ Indicator variables } & \multirow{2}{*}{$\begin{array}{c}\begin{array}{c}\text { Full sample } \\
(\mathrm{N}=1,345)\end{array} \\
\mathrm{M}(\mathrm{SD})\end{array}$} & \multicolumn{2}{|c|}{$\begin{array}{c}\text { Class 1 } \\
(\mathrm{n}=392) \\
29 \% \text { of sample }\end{array}$} & \multicolumn{2}{|c|}{$\begin{array}{c}\text { Class } 2 \\
(\mathrm{n}=270) \\
20 \% \text { o of sample }\end{array}$} & \multicolumn{2}{|c|}{$\begin{array}{c}\text { Class } 3 \\
(\mathrm{n}=257) \\
19 \% \text { of sample }\end{array}$} & \multicolumn{2}{|c|}{$\begin{array}{c}\text { Class } 4 \\
(\mathrm{n}=233) \\
17 \% \text { of sample }\end{array}$} & \multicolumn{2}{|c|}{$\begin{array}{c}\text { Class 5 } \\
(\mathrm{n}=193) \\
14 \% \text { of sample }\end{array}$} \\
\hline & & $\mathrm{M}(\mathrm{SD})$ & $Z^{\dagger}$ & $\mathrm{M}(\mathrm{SD})$ & $Z^{\dagger}$ & $\mathrm{M}(\mathrm{SD})$ & $Z^{\dagger}$ & $\mathrm{M}(\mathrm{SD})$ & $\mathrm{Z}^{\dagger}$ & $\mathrm{M}(\mathrm{SD})$ & $\mathrm{Z}^{\dagger}$ \\
\hline Knowledge about AVs & $2.10(0.67)$ & $1.93(0.63)$ & $-.25^{* * *}$ & $2.07(0.60)$ & -.04 & $2.12(0.63)$ & .02 & $2.17(0.74)$ & .10 & $2.38(0.72)$ & $.41 * * *$ \\
\hline First to buy AV & $2.00(1.19)$ & $1.00(0.00)$ & $-.84 * * *$ & $1.00(0.00)$ & $-.84 * * *$ & $2.00(0.00)$ & .00 & $3.00(0.00)$ & $.84 * * *$ & $4.24(0.43)$ & $1.88 * * *$ \\
\hline Ever buy AV & $2.80(1.31)$ & $1.32(0.56)$ & $-1.13 * * *$ & $3.01(0.99)$ & $.17 *$ & $3.23(1.00)$ & $.34 * * *$ & $3.42(0.83)$ & $.48 * * *$ & $4.17(0.79)$ & $1.05^{* * *}$ \\
\hline Share AVs & $2.95(1.33)$ & $1.47(0.75)$ & $-1.12 * * *$ & $3.54(0.89)$ & $.44 * * *$ & $3.35(1.04)$ & $.30 * * *$ & $3.46(0.93)$ & $.38 * * *$ & $3.99(1.01)$ & $.78 * * *$ \\
\hline Perceived benefits of AVs & $15.03(3.74)$ & $12.28(3.77)$ & $-.74 * * *$ & $16.33(2.55)$ & $.35 * * *$ & $15.82(3.20)$ & $.21 * *$ & $\begin{array}{l}15.44 \\
(3.56)\end{array}$ & .11 & $17.27(2.65)$ & $.60 * * *$ \\
\hline Concerns about AVs & $6.16(2.14)$ & $7.25(2.03)$ & $.51 * * *$ & $5.79(1.92)$ & $-.17 * *$ & $5.64(1.96)$ & $-.24 * * *$ & $5.55(1.98)$ & $-.28 * * *$ & $5.86(2.27)$ & -.14 \\
\hline Predictor variables & \multicolumn{10}{|c|}{$\mathrm{M}(\mathrm{SD})$} & \\
\hline Age in years ${ }^{* * *}$ & $42.26(17.40)$ & \multicolumn{2}{|c|}{$48.41(18.77)^{\mathrm{a}}$} & \multicolumn{2}{|c|}{$42.14(16.86)^{b}$} & \multicolumn{2}{|c|}{$38.24(15.45)^{\mathrm{bc}}$} & \multicolumn{2}{|c|}{$40.23(16.82)^{\mathrm{bc}}$} & \multicolumn{2}{|c|}{$37.46(14.56)^{\mathrm{c}}$} \\
\hline Education $^{* * * *}$ & $3.17(1.04)$ & \multicolumn{2}{|c|}{$2.97(1.00)^{\mathrm{a}}$} & \multicolumn{2}{|c|}{$3.26(1.04)^{\mathrm{b}}$} & \multicolumn{2}{|c|}{$3.11(1.05)^{\mathrm{ab}}$} & \multicolumn{2}{|c|}{$3.16(1.01)^{\mathrm{ab}}$} & \multicolumn{2}{|c|}{$3.56(1.04)^{\mathrm{c}}$} \\
\hline Annual income $e^{* * *}$ & $3.47(1.74)$ & \multicolumn{2}{|c|}{$3.12(1.68)^{\mathrm{a}}$} & \multicolumn{2}{|c|}{$3.78(1.87)^{\mathrm{bc}}$} & \multicolumn{2}{|c|}{$3.40(1.65)^{\mathrm{ac}}$} & \multicolumn{2}{|c|}{$3.58(1.73)^{\mathrm{bc}}$} & \multicolumn{2}{|c|}{$3.66(1.67)^{\mathrm{c}}$} \\
\hline $\begin{array}{l}\text { Number of crashes in last } \\
10 \text { years as driver }{ }^{* * * *}\end{array}$ & $.64(0.91)$ & \multicolumn{2}{|c|}{$.47(0.78)^{\mathrm{a}}$} & \multicolumn{2}{|c|}{$.61(0.89)^{\mathrm{ab}}$} & \multicolumn{2}{|c|}{$.76(0.98)^{\mathrm{b}}$} & \multicolumn{2}{|c|}{$.73(0.94)^{b}$} & \multicolumn{2}{|l|}{$.76(1.02)^{\mathrm{b}}$} \\
\hline $\begin{array}{l}\text { Number of crashes in last } \\
10 \text { years as passenger } * * *\end{array}$ & $.37(0.71)$ & \multicolumn{2}{|c|}{$.26(0.63)^{\mathrm{a}}$} & \multicolumn{2}{|c|}{$.30(0.62)^{\mathrm{ab}}$} & \multicolumn{2}{|c|}{$.45(0.78)^{\mathrm{bc}}$} & \multicolumn{2}{|c|}{$.39(0.68)^{\mathrm{abc}}$} & \multicolumn{2}{|l|}{$.54(0.90)^{\mathrm{c}}$} \\
\hline Driving history ${ }^{* * *}$ & $3.50(.84)$ & \multicolumn{2}{|c|}{$3.70(.67)^{\mathrm{a}}$} & $3.61{ }^{\prime}$ & & $3.32(.5$ & & 3.48 & $(.85)^{\mathrm{bc}}$ & $3.17(.99)$ & \\
\hline Driving enjoyment ${ }^{* * * *}$ & $3.44(1.15)$ & $3.57(1$ & $5)^{\mathrm{ac}}$ & $3.26(1$ & $2)^{b}$ & $3.39(1$. & $1)^{\mathrm{ab}}$ & 3.27 & $1.14)^{\mathrm{b}}$ & $3.71(1.18$ & \\
\hline $\begin{array}{l}\text { Hrs per week on public } \\
\text { transport for work } \\
\text { commute }^{*}\end{array}$ & $1.49(5.30)$ & $1.05(6$ & $20)^{\mathrm{a}}$ & $1.09(2$ & $8)^{\mathrm{ab}}$ & $1.72(4$. & $9)^{\mathrm{ab}}$ & 1.68 & $6.98)^{\mathrm{ab}}$ & $2.42(3.95$ & \\
\hline $\begin{array}{l}\text { Hrs on public transport for } \\
\text { other trips }\end{array}$ & $1.32(5.53)$ & $.98(4$ & & $1.02(3$ & & $1.82(8$ & & 1.12 & $(5.73)$ & $2.09(4.24$ & \\
\hline
\end{tabular}




\begin{tabular}{|c|c|c|c|c|c|c|}
\hline $\begin{array}{l}\text { Hrs driving per week for } \\
\text { work commute }\end{array}$ & $3.86(8.31)$ & $3.36(6.83)$ & $3.39(7.71)$ & $4.98(13.11)$ & $3.48(5.58)$ & $4.74(7.52)$ \\
\hline $\begin{array}{l}\text { Hours driving per week for } \\
\text { other trips }\end{array}$ & $5.62(7.94)$ & $5.24(6.33)$ & $5.25(7.18)$ & $7.06(11.91)$ & $4.99(5.50)$ & $6.06(8.70)$ \\
\hline \multicolumn{7}{|c|}{$\mathrm{n}(\%)$} \\
\hline Gender - Male & $689(51)$ & $187(48)$ & $131(49)$ & $126(54)$ & $130(51)$ & $115(60)$ \\
\hline $\begin{array}{l}\text { Location - } \\
\text { Metropolitan* }\end{array}$ & $1058(79)$ & $289(74) a$ & $219(81) \mathrm{b}$ & $201(78) \mathrm{ab}$ & $194(83) b$ & $155(80) \mathrm{ab}$ \\
\hline Lost licence - Yes & 159 & $45(12)$ & $37(14)$ & $28(12)$ & $28(11)$ & $21(11)$ \\
\hline Dependent children - Yes & 559 & $148(38)$ & $111(41)$ & $104(45)$ & $106(41)$ & $90(47)$ \\
\hline $\begin{array}{l}\text { Transport elderly/disabled } \\
\text {-Yes** }\end{array}$ & $235(17)$ & $60(15)^{\mathrm{a}}$ & $39(14)^{\mathrm{a}}$ & $37(16)^{\mathrm{a}}$ & $48(19)^{\mathrm{ab}}$ & $51(26)^{\mathrm{b}}$ \\
\hline $\begin{array}{l}\text { Consumed alcohol at risky } \\
\text { level }{ }^{\dagger \dagger}\end{array}$ & $156(12)$ & $43(11)$ & $32(12)$ & $22(14)$ & $25(11)$ & $34(18)$ \\
\hline
\end{tabular}

Note: ${ }^{\dagger}$ comparisons made between each class and the full sample; ${ }^{\dagger \dagger}$ Those drinking an average of more than two standard drinks per day were classified as drinking at levels associated with long-term harm from alcohol (as per NHMRC 2009);* $\mathrm{p}<.05, * * \mathrm{p}<.01, * * * \mathrm{p}<.001$; sharing a letter in the same row indicates a non-significant difference across groups using ANOVAs for continuous variables and chi-square tests for discrete variables; Class $1=$ "Nonadopters"; Class 2 = "Ride-sharing only"; Class 3 = "AV ambivalent"; Class 4 = "Likely adopters"; Class 5 = "First movers". 


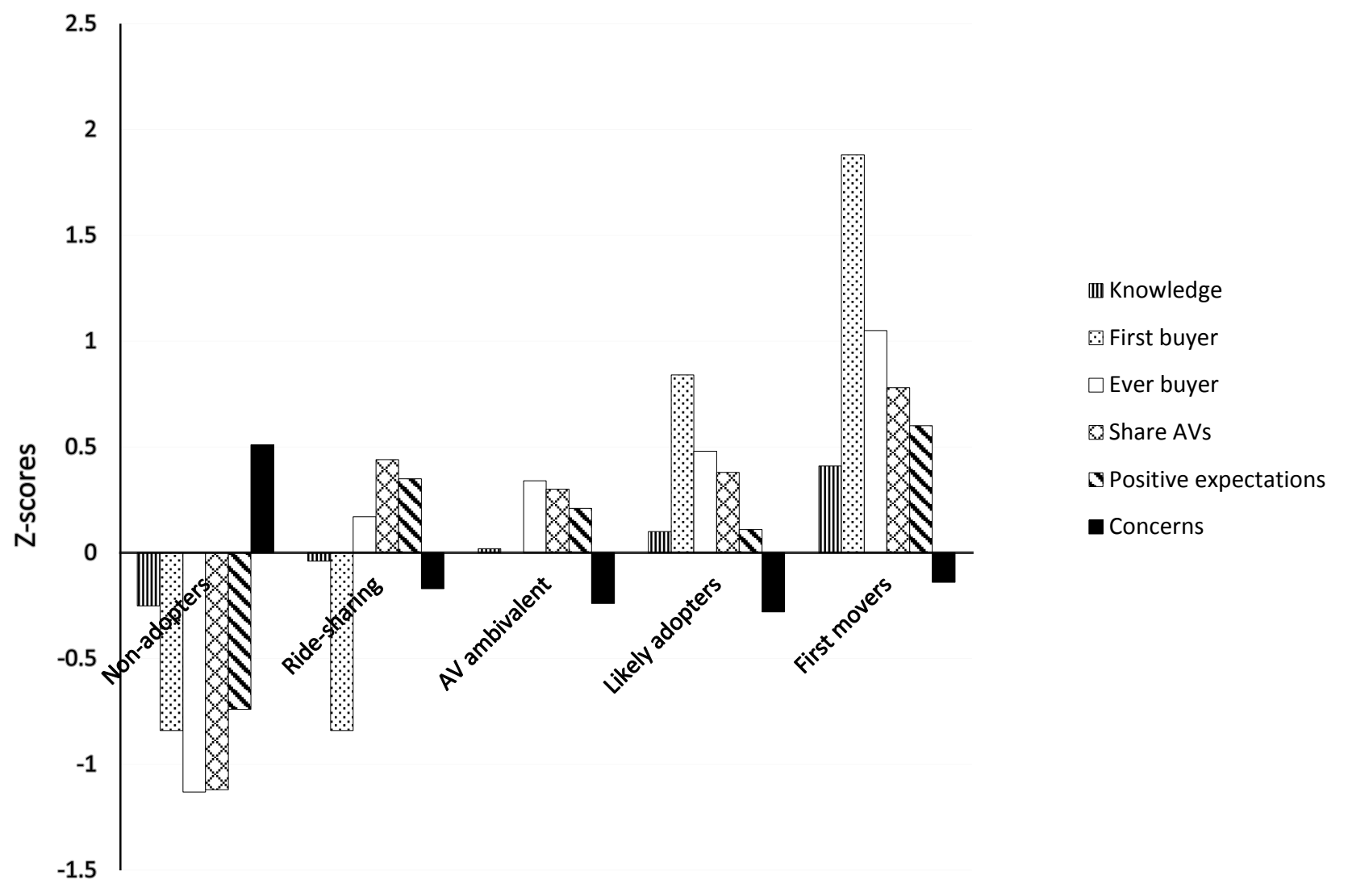

Figure 1. Graphic presentation of the 5-class latent profile solution 